\title{
Optimum Dimensions of Suspension Bridges Considering Natural Period
}

\author{
Jewel Sarker ${ }^{1}$, Dr. Tanvir Manzur ${ }^{2}$

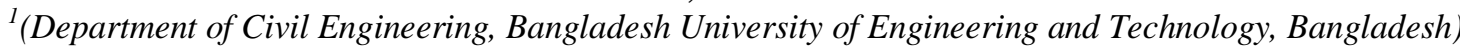 \\ ${ }^{2}$ (Assistant Professor, Department of Civil Engineering, Bangladesh University of Engineering and Technology, \\ Bangladesh)
}

\begin{abstract}
Suspension bridge is an efficient structural system particularly for large spans. Many difficulties related to design and construction feasibility arises due to its long central span. There are many suspension bridges around the world and dynamic behavior has been found to be the primary concern for those bridges. Natural period of a suspension bridge mainly dependent on the span and other structural dimensions related to the stiffness. In the present study, the effects of structural parameters like deck depth and tower height on natural period of suspension bridges having different central spans are conducted. Natural periods are analyzed by modal analysis for central span lengths ranges from 600m to $1400 \mathrm{~m}$. The modal analysis is performed by finite element software package SAP2000. For each central span, tower heights and deck depth are varied and the consequences of these variations on the natural periods of various types of vibration modes are investigated and dominant mode for each span is recognized. Obtained values from the analysis were utilized to plot three dimensional surfaces representing correlation among natural period, deck depth, tower height, and span, using MATLAB functions. A relationship among tentative optimum deck depth, optimum tower height and central span of suspension bridge is developed for obtaining minimum natural period. This relationship can be used to obtain the tentative optimum dimensions of a suspension bridge with central span between $600 \mathrm{~m}$ to $1400 \mathrm{~m}$.
\end{abstract}

Keywords: suspension bridge, natural period, optimum dimensions, modal analysis.

\section{Introduction}

Suspension bridge is a type of bridge that has a larger span than any other form of bridges. As it get larger span it become more flexible structure. As a structure get flexible its behavior under dynamic load become more complicated [1]. Wind load and earthquake load are dynamic in nature and in the design of a suspension bridge these loads are in major concern [2]. To design for such loads the dynamic behavior must be controlled [3]. The way to do this is controlling the natural frequency of the structure. Hence to control the dynamic behavior the effect of different structural element of the bridge on the dynamic behavior especially on the natural frequency of the suspension bridge is needed to understand.

Since suspension bridge is an indeterminate structure, finite element method is used to analyze some models of suspension bridge for different span [4][5]. This study concentrates on the effect of different structural element on the natural period of suspension bridge along its span and attempts to provide the designers a set of guideline that would provide them indication of the optimum sizes and dimensions of various structural elements of suspension bridges of different span.

\section{Assumptions For Analysis}

An attempt to analyze a suspension bridge and account accurately for all aspects of behavior of all the components and materials, even if their sizes and properties were known, would be virtually impossible [6]. Simplifying assumptions are necessary to reduce the problem to a viable size.

Although a wide variety of assumptions is viable, some more valid than others, the ones adopting in forming a particular model will depend on the arrangement of the structure, its anticipated mode of behavior, and the type of analysis [7]. The most common assumptions are as follows:

\subsection{Materials}

The materials of the structures and the structural components are linearly elastic. This assumption allows the superposition of actions and deflections and, hence, the use of linear methods of analysis. The development of linear methods and their solution by computer has made it possible to analyze the large complex statically indeterminate structures. 


\subsection{Participating Components}

Only the primary structural components participate in the overall behavior. The effect of secondary structural components and non structural components are assumed to be negligible and conservative. Although this assumption is generally valid, exception occurs.

\subsubsection{The Deck}

The decks are assumed to be rigid in plane. This assumption causes the horizontal plan displacements of all vertical elements at a floor level to be definable in terms of the horizontal plane rigid body rotation and translation of the floor slab. Thus the number of unknown displacements to be determined in the analysis is greatly reduced.

\subsubsection{Negligible Stiffness}

Component stiffness of relatively small magnitude are assumed negligible. These often include, for example, the transverse bending stiffness of slabs, the minor axis stiffness cable etc. The use of this assumption should be dependent on the role of the component in the structures behavior.

\subsubsection{Negligible Deformations}

Deformations that are relatively small and of little influence, are neglected. These include the shear and axial deformations of girder, in plane bending and shear deformation of floor slabs, and the axial deformations of towers.

\section{Finite Element Model And Analysis}

It is necessary for the intermediate and final stages of the design to obtain a reasonably accurate estimate of the structure deflections and member forces. With the wide availability of structural analysis programs and powerful computers it is now possible to solve very large and complex structural models. Some of the more gross approximations are used for a preliminary analysis [8]. The structural model for an accurate analysis should represent in a more detailed way all the major active components of the prototype structure.

In this study a number of suspension bridges with different central span with corresponding side span and with different dimensions of various parameters were modeled and analyzed. The total width of the deck is taken 30m for a six-lane road way. Computer software SAP2000 was used for finite element modeling of those bridges. As suspension bridge is a composite type of structure, it consists of tower, bridge deck, floor slab, hanger, main cable, anchorage etc. The roadway is not modeled in this study and there no damper is used to control the frequencies of the bridge.

After a three-dimensional finite-element model is constructed, and modal analysis is performed. The free vibration analysis is then conducted based on this static equilibrium position. The three-dimensional finiteelement model is constructed using linear elastic cable elements for the cables, and elastic or rigid body constrains for the connections between the deck and the hangers. The modeling of these components, the connections between the deck and the tower, as well as the boundary conditions are described in the following.

\subsection{Tower Modeling}

The bridge towers are represented by three-dimensional multilevel portal frames. The towers and the cross beam are modeled using the linear elastic frame section based on gross cross-section properties. All elements are modeled based on centerline. Therefore, offsets are assigned to diagonal and lateral beam bracings to account for the rigid end effect. The node points for the upper segments of towers are placed at the cable anchorage locations. Rigid links are accordingly assigned to the tower elements to model the joints. The material properties and the geometrical properties of the tower and the cross beams are summarized in Tables 1 .

\subsection{Deck Modeling}

The bridge deck consists of concrete rectangular box girder for the whole portion. To simplify the computation, the bridge deck is modeled using section designer and designed as a box girder. Stiffness and masses (for both the translational and the rotational directions) are calculated and assigned to the box girder of the deck to stimulate the actual stiffness-mass system of the deck. The box girder is composed of deck elements, and most of the nodes are arranged corresponding to the anchor locations of the cables. The cable anchorages and the box girder are connected by mass less rigid links. The material properties of concrete used in the bridge deck can be found in Table 1. As for the nonstructural components, such as parapets, train tracks, and beacons, their contribution to the structural rigidity is expected to be quite insignificant and therefore is ignored in the model. The material properties for the virtual monolithic deck and the equivalent cross-sectional properties are 
also summarized in Table 1. Since the cross-sections of the deck are very rigid, the corresponding warping constants are very large. Consequently, no cross-sectional warping is anticipated.

Table 1: Material properties of suspension bridge elements.

\begin{tabular}{|c|c|c|c|}
\hline Components & $\begin{array}{l}\text { Modulus of elasticity } \\
\qquad\left(\mathrm{KN} / \mathrm{m}^{2}\right)\end{array}$ & $\begin{array}{l}\text { Mass density } \\
\quad\left(\mathrm{kg} / \mathrm{m}^{3}\right)\end{array}$ & Poisson's ratios \\
\hline Concrete Tower & $2.5 \times 10^{7}$ & 2402.7696 & 0.2 \\
\hline $\begin{array}{l}\text { Cross Beam of Tower } \\
\text { (Steel Section) }\end{array}$ & $1.999 \times 10^{8}$ & 7849.0474 & 0.3 \\
\hline $\begin{array}{c}\text { Concrete Box Girder } \\
\text { Deck }\end{array}$ & $2.5 \times 10^{7}$ & 2402.7696 & 0.2 \\
\hline $\begin{array}{c}\text { Steel Wire for } \\
\text { Cables \& Hangers }\end{array}$ & $1.999 \times 10^{8}$ & 7849.0474 & 0.3 \\
\hline
\end{tabular}

\subsection{Cable \& Hanger Modeling}

The main cables and hangers are modeled using linear elastic truss elements. For an inclined cable, the force-deformation relation is expected to be nonlinear due to cable tension and cable sagging. This nonlinear stiffness behavior can be taken into account by linearizing the cable stiffness using the concept of an equivalent modulus of elasticity. The hangers are spaced $20 \mathrm{~m}$ in both side of the deck. The main cable and hangers are made of bundles of stands with each bundle consisting of several wires. The total cross sectional area of the cable is found by summing up the total area of the wires in the cross-section. For each main cable and hanger, the Ernst equation is employed to calculate its equivalent modulus

$$
E_{e q}=\frac{E}{1+\frac{(w l)^{2} \times A E}{12 T^{3}}}
$$

Where

$$
\begin{array}{ll}
\mathrm{E}_{\mathrm{eq}} & =\text { Equivalent modulus of elasticity; } \\
\mathrm{E} & =\text { Modulus of elasticity for the cable; } \\
\mathrm{A} & =\text { Cross-sectional area; } \\
\mathrm{T} & =\text { Tension in cable; } \\
\mathrm{w} & =\text { Cable weight per unit length; and } \\
1 & =\text { Horizontal projected length of a cable; }
\end{array}
$$

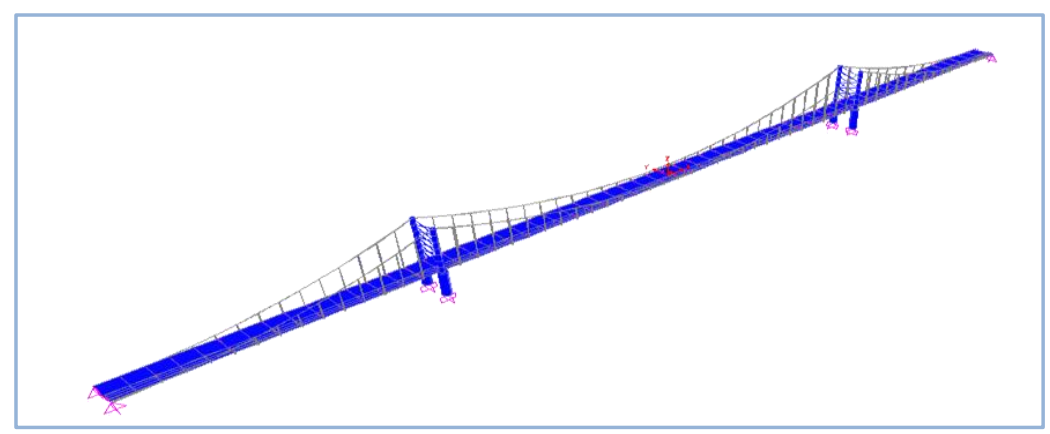

Figure 1: SAP2000 Modeling (A Suspension Bridge 3D View).

\subsection{Modal Analysis}

The developed detailed model of this study has more degrees of freedom than needed for accurate frequency analysis. The model is desired in static analysis to produce accurate estimation for stiffness. However, it might results in undesired modes of vibration particularly when there are very flexible elements, such as cables. The traditional Eigen vectors procedure is used for the modal analysis. Only first 20 modes are considered in this study for each of these models.

For $600 \mathrm{~m}$ central span first two modes shapes are shown in the Figure 2.From the obtained output it has been found that as the central span of a suspension bridge increases the lateral stiffness of the bridge 
decreases. For the central span $800 \mathrm{~m}$ and smaller the governing mode is vertical vibration and for the central span $1000 \mathrm{~m}$ and larger the governing mode becomes lateral vibration.

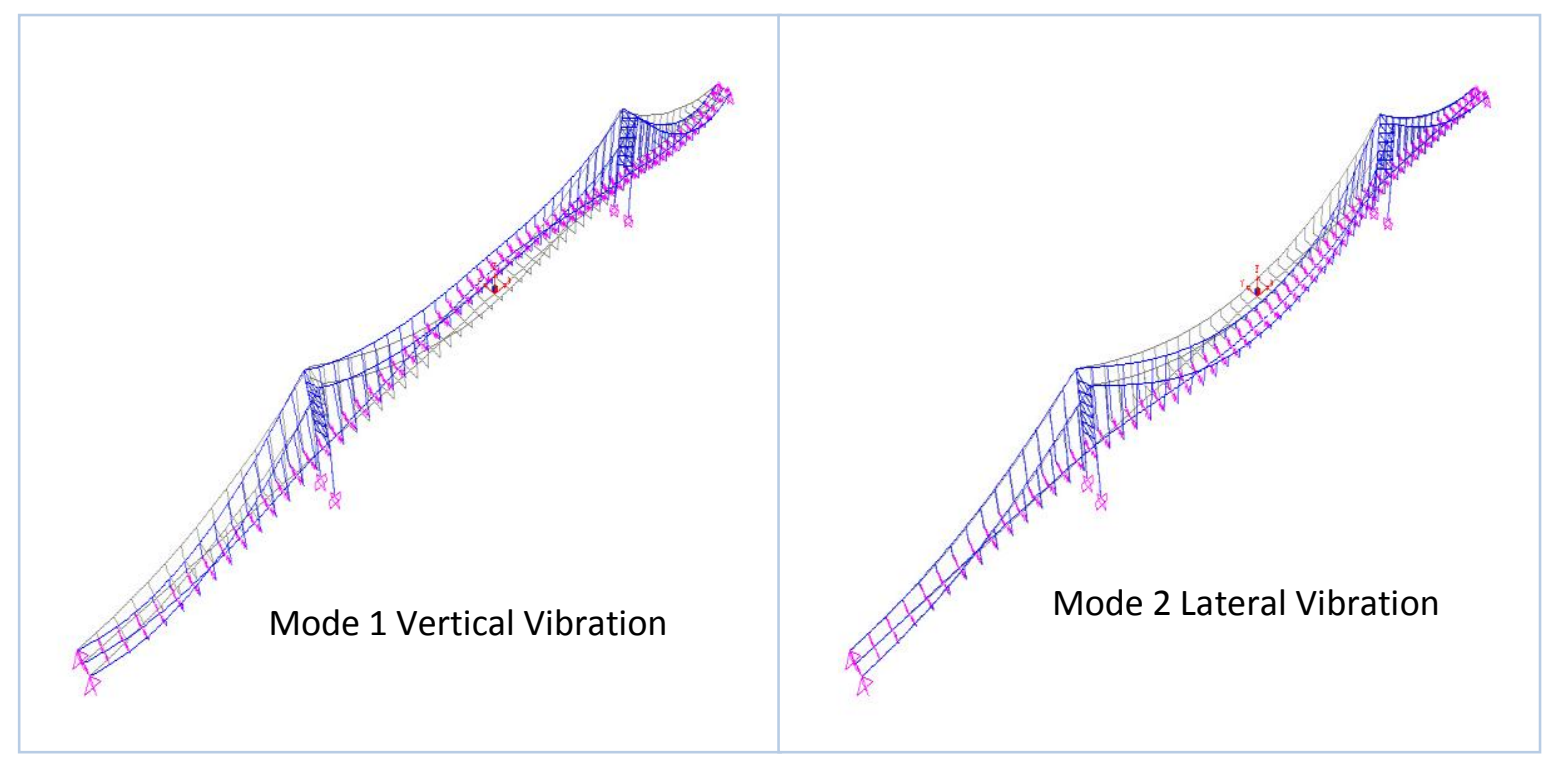

Figure 2: Different mode shapes.

\section{Results and Discussions}

\subsection{Effects of Deck Depth and Tower Height}

Here only effects on $600 \mathrm{~m}$ central span are discussed. From Figure 3 it is found that natural period for vertical vibration decrease with the increase of deck depth for all tower height and optimum tower height central span ratio is found $1: 6$. For this $600 \mathrm{~m}$ central span $100 \mathrm{~m}$ of tower height and $4.8 \mathrm{~m}$ of deck depth is preferable to obtain minimum natural period for vertical vibration according to this study.

\section{Central Span 600m}

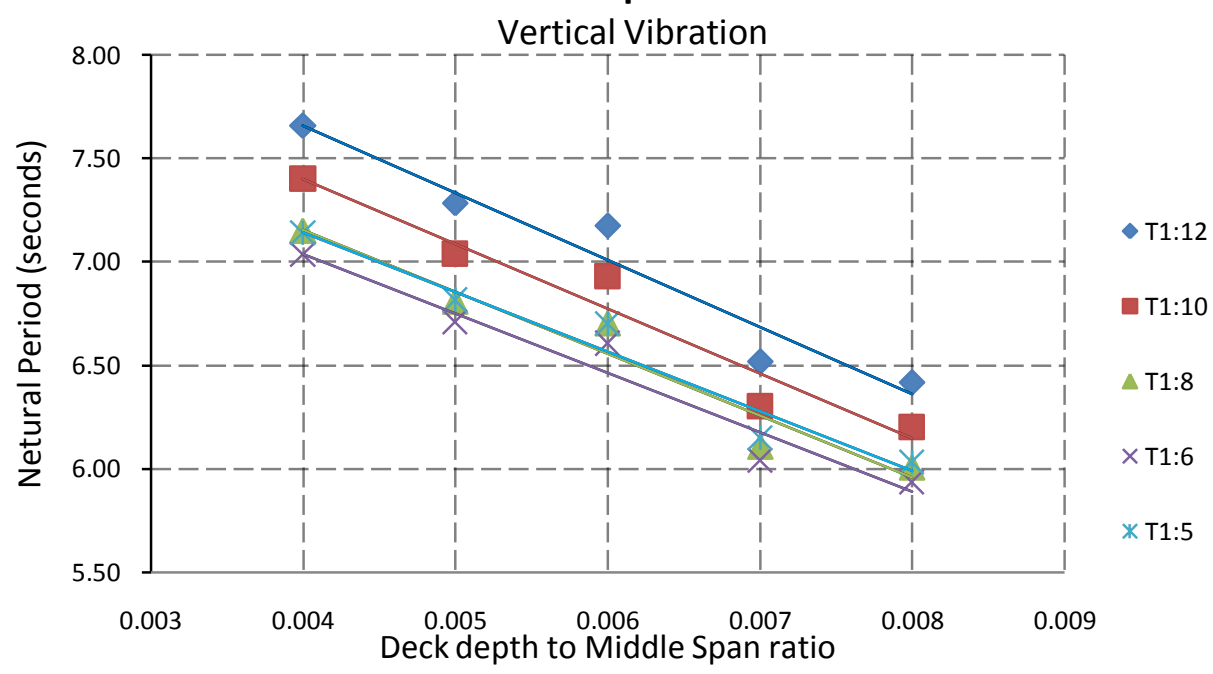

Figure 3: Effects of Deck Depth and Tower Height on Vertical Vibration for 600m Central Span. 


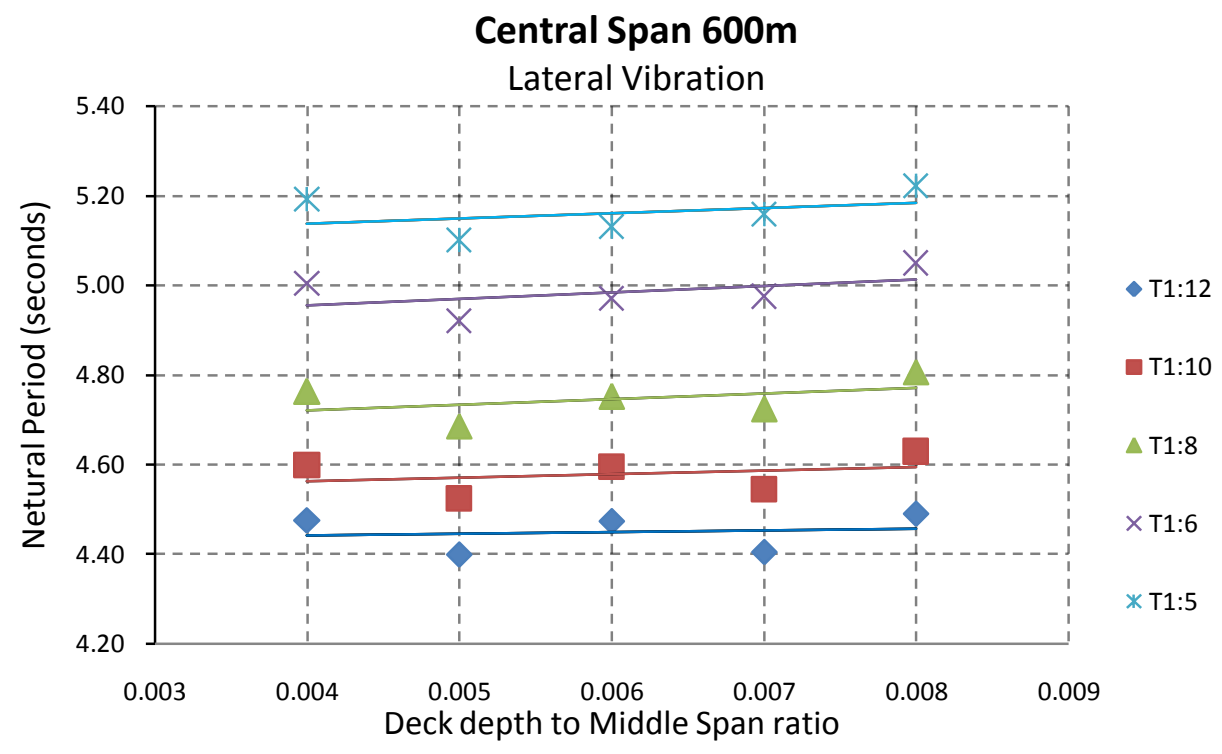

Figure 4: Effects of Deck Depth and Tower Height on Lateral Vibration for 600m Central Span.

For lateral vibration the effect of deck depth changes slightly with the changes of deck depth (Figure 4) while changes in the tower height affect largely on the natural period. The optimum tower height span ratio is found 1:12 which leads to a tower height of $50 \mathrm{~m}$.

\subsection{Findings and Applications}

Values obtained from finite element analysis were utilized to plot three dimensional surfaces representing correlation among natural period, deck depth, tower height, and span, using MATLAB functions. These graphs can be used to determine the desired optimum parameters of the suspension bridges.

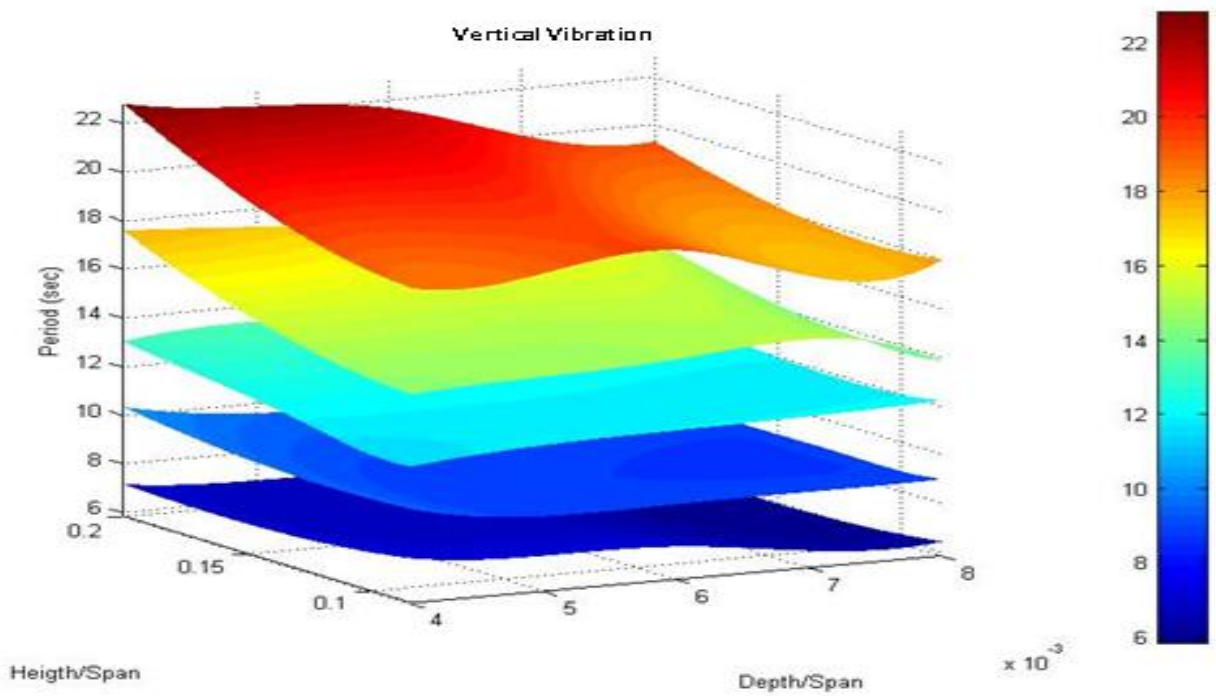

Figure 5: Natural periods for vertical vibration of suspension bridges of different span.

\subsubsection{Optimum Dimensions for Vertical Vibration}

The surfaces shown in Figure 5 represent natural periods for vertical vibration of suspension bridges of central span of $600 \mathrm{~m}-1400 \mathrm{~m}$. From these surfaces a minimum natural period is obtained with corresponding deck depth to span ratio and tower height to span ratio. They are shown in Table 2. 
Table 2: Minimum Natural Period for Vertical Vibration of Suspension Bridges.

\begin{tabular}{|cccc|} 
Central Span (m) & Deck Depth/Span & Tower Height/Span & Natural Period (sec) \\
\hline 600 & 0.0076 & 0.1552 & 5.8278 \\
800 & 0.0072 & 0.1269 & 8.6953 \\
1000 & 0.0040 & 0.0928 & 11.3646 \\
1200 & 0.0080 & 0.1034 & 13.6826 \\
1400 & 0.0080 & 0.1010 & 17.2708 \\
\hline
\end{tabular}

These optimum values of deck depth/span, tower height/span and natural periods are plotted against central span of suspension bridge in Figure 7, Figure 8 and Figure 9 respectively. One can obtain optimum values for desired central span using these graphical charts for the vertical vibration of suspension bridge with the central span ranged between $600 \mathrm{~m}-1400 \mathrm{~m}$.

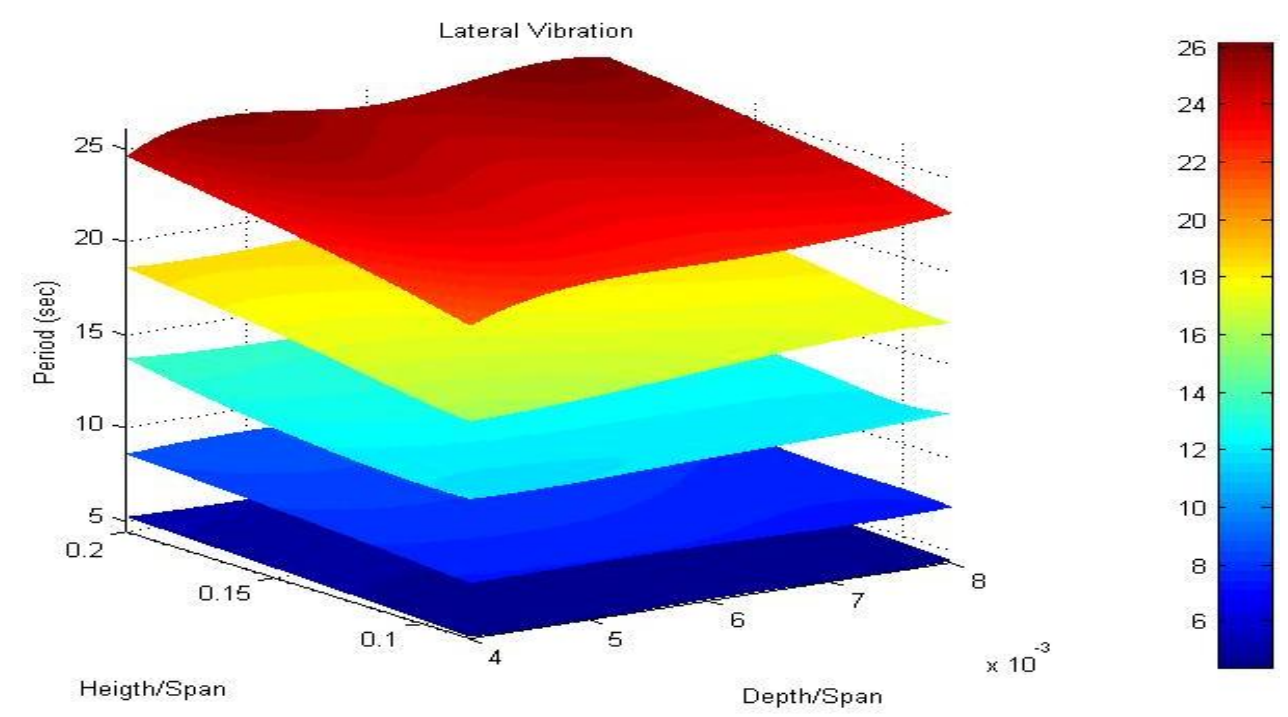

Figure 6: Natural periods for lateral vibration of suspension bridges of different span.

\subsubsection{Optimum Dimensions for Lateral Vibration}

The natural periods for lateral vibration are represented by the surfaces shown in Figure 6 for suspension bridges of central span of $600 \mathrm{~m}-1400 \mathrm{~m}$. From these surfaces a minimum natural period is obtained with corresponding deck depth to span ratio and tower height to span ratio. Obtained values are shown in Table 3 .

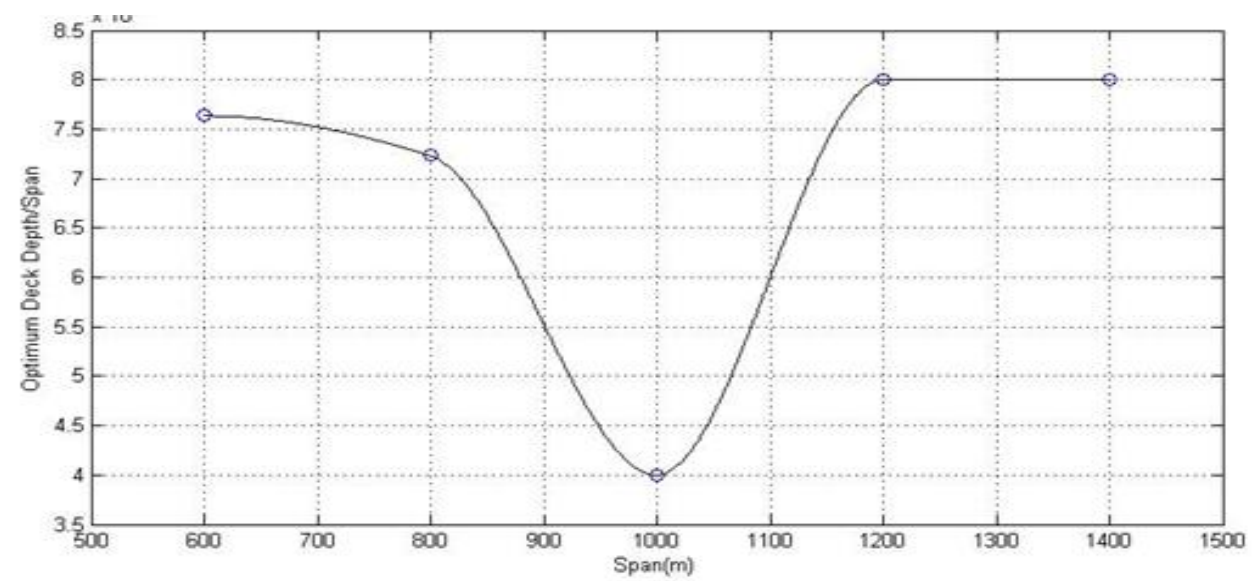

Figure 7: Optimum deck depth/span of different central span for vertical vibration 


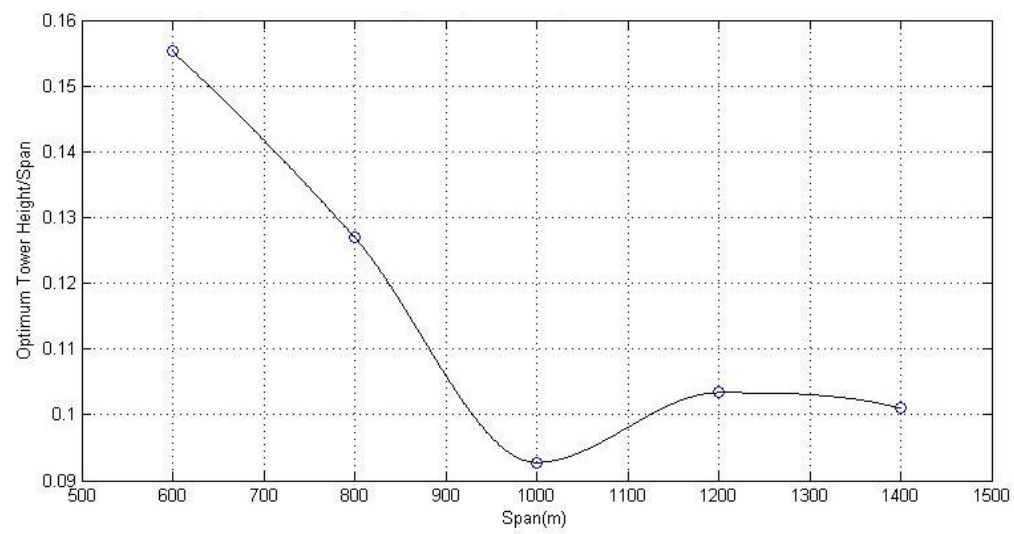

Figure 8: Optimum tower height/span of different central span for vertical vibration.

Table 3: Minimum Natural Period for Lateral Vibration of Suspension Bridges.

\begin{tabular}{|cccc|} 
Central Span $(\mathrm{m})$ & Deck Depth/Span & $\begin{array}{c}\text { Tower Height/Span } \\
\text { Natural Period } \\
(\mathrm{sec})\end{array}$ \\
\hline 600 & 0.0047 & 0.0833 & 4.3865 \\
\hline 800 & 0.0073 & 0.0833 & 7.2618 \\
1000 & 0.0047 & 0.0928 & 11.7782 \\
1200 & 0.0040 & 0.0833 & 16.0654 \\
1400 & 0.0040 & 0.0833 & 21.1926 \\
\hline
\end{tabular}

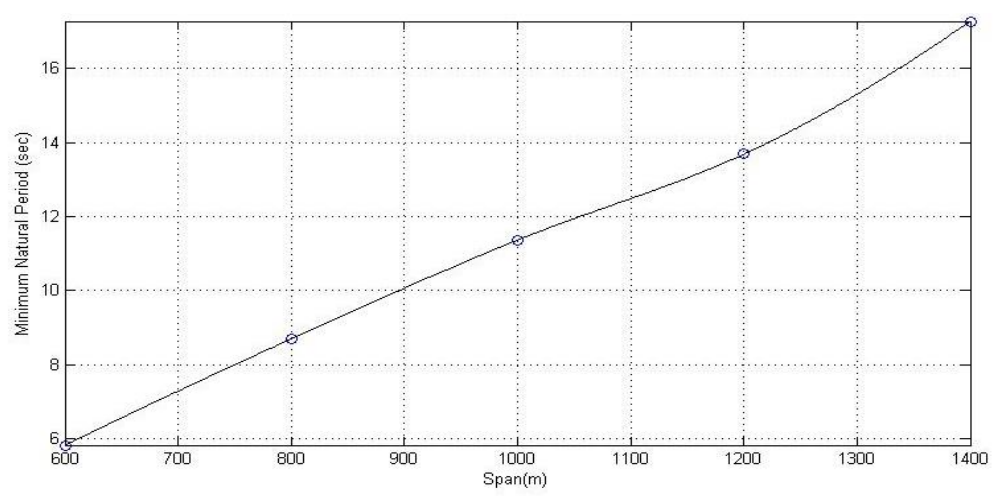

Figure 9: Minimum natural period of different central span for vertical vibration.

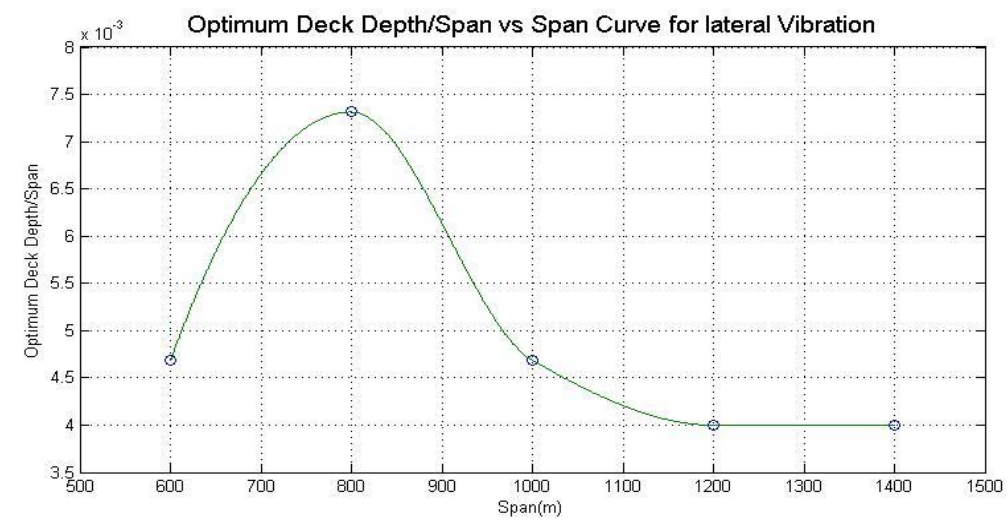

Figure 10: Optimum deck depth/span of different central span for lateral vibration. 
These optimum values of deck depth/span, tower height/span and natural periods are plotted against central span of suspension bridge in Figure 9, Figure 10 and Figure 11 respectively. One can obtain optimum values for desired central span from these figures within the central span ranges from $600 \mathrm{~m}-1400 \mathrm{~m}$.

\subsection{Tentative Optimum Deck Depth and Tower Height}

By using the functions of Figures $7-12$ a relationship is obtained in MATLAB (Figure 13). By using this relationship one can determine the optimum deck depth and optimum tower height for desired central span between $600 \mathrm{~m}$ to $1400 \mathrm{~m}$. This relationship determines the dominant vibration mode and obtains corresponding optimum dimensions. And for that dimensions calculates the optimum natural periods.

These optimum values of deck depth/span, tower height/span and natural periods are plotted against central span of suspension bridge in Figure 9, Figure 10 and Figure 11 respectively. One can obtain optimum values for desired central span from these figures within the central span ranges from $600 \mathrm{~m}-1400 \mathrm{~m}$.

Using MATLAB functions, for desired central span optimum deck depth and tower height can be evaluated. In Figure 13, there is shown a output of MATLAB functions for a central span of 900m. Using this optimum deck depth and tower height a model was developed in SAP2000. Obtained results are compared in Table 4. From Table 4 it is found that the variation of this application is about $6 \%$.

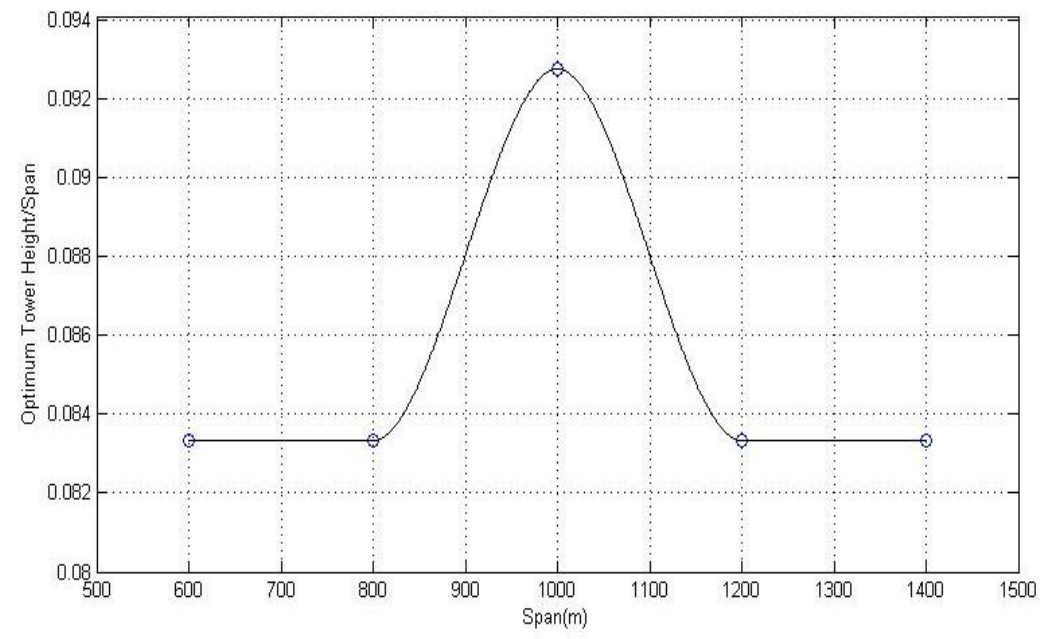

Figure 11: Optimum tower height/span of different central span for lateral vibration.

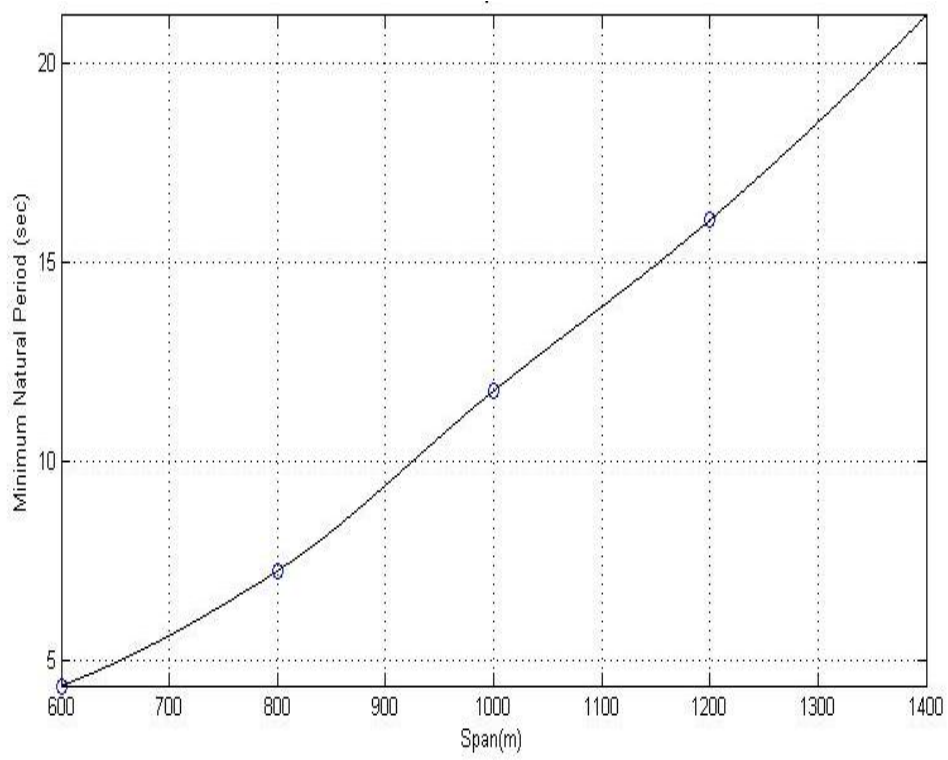

Figure 12: Minimum natural period of different central span for lateral vibration. 
Table 4: Variations of graphical results from analysis results.

\begin{tabular}{|cccc|}
\hline & Graphical Result & $\begin{array}{c}\text { SAP2000 } \\
\text { Result }\end{array}$ & Variation \\
\hline Central span (m) & 900 & 900 & \\
\hline Deck depth (m) & 4.9737 & 4.98 & \\
\hline Tower height (m) & 95.3816 & 95.4 & \\
\hline Dominant vibration & Vertical & Vertical & \\
\hline Mode 1 (natural period & 10.0654 & 10.682323 & $-5.775 \%$ \\
\hline $\begin{array}{c}\text { (sec)) } \\
\text { Mode 2 (natural period } \\
\text { (sec)) }\end{array}$ & 9.74457 & 9.639744 & $1.087 \%$ \\
\hline
\end{tabular}

\begin{tabular}{|c|c|c|c|}
\hline A final_fig & & & $-\square x$ \\
\hline & Your Desired Span (m): & $\overline{900}$ & \\
\hline & Calculate & Reset & \\
\hline & Dominant mode & Vertical Vibration & \\
\hline & Optimum Deck Depth (m) & 4.97374 & \\
\hline & Optimum Tower Height (m) & 95.3816 & \\
\hline & Mode 1 ( Natural Period (sec)) & 10.0654 & \\
\hline & Mode 2 ( Natural Period (sec)) & 9.74457 & \\
\hline
\end{tabular}

Figure 13: Optimum deck depth and tower height determination.

\section{Conclusion}

The conclusions of the study can be summarized as follows,

From the analysis it is noted that as the central span increases the lateral stiffness of the suspension bridge decreases. The lateral vibration mode becomes dominant once the length central span exceeds $1000 \mathrm{~m}$.

The tower height has significant effect on the natural period of a suspension bridge. As the tower height to span ratio decrease, the natural period for vertical vibration decreases with the increment of the central span length. For lateral vibration, it is observed that a low tower height to span ratio is favorable to obtain minimum natural period.

Effect of deck depth on the natural period is also prominent for both vertical and lateral vibration. For vertical vibration, increase in the deck depth to span ratio is found to be effective to obtain lower value of natural period. On the other hand, decrease in the deck depth to span ratio leads to obtain minimum natural period for lateral vibration.

MATLAB functions were used to interrelate natural period, deck depth, tower height and central span of suspension bridge and are shown graphically in the study. From this interrelated graphical presentation, a 
program was developed which can be used to determine the tentative optimum dimensions of a suspension bridge considering natural period.

Validity of the developed program was checked by analyzing a suspension bridge in SAP2000 using the dimensions obtained by the program. Natural periods, obtained from the program and the SAP2000 analysis, were then compared. Around $6 \%$ variation was found between these two values.

\section{References}

[1]. Anil k. Chopra, Dynamics of structures: theory and application to earthquake engineering (Prentice Hall, Upper Saddle River, New Jersey, 1995).

[2]. Abdel- Ghaffar. Dynamic Analysis of Suspension Bridge Structures, EERL 76-01, Earthquake Engineering Research Laboratory, California Institute of Technology, Pasadena, California, 1976.

[3]. Moisseiff, L. S. and Lienhard, F., Suspension bridge under the action of lateral forces, Trans. ASCE, 58, 1933.

[4]. Brotton, D. M., A general computer programme for the solution of suspension bridgeproblems, Struct. Eng., 44, 1966.

[5]. Saafan, A. S., Theoretical analysis of suspension bridges, Proc. ASCE, 92, ST4,1966.

[6]. I. Konishi and Y. Yamada, Earthquake Responses of a Long Span Suspension Bridge, Proceedings of the Second World Conference on Earthquake Engineering, Tokyo, Vol. 2, 1960, pp. 863-875.

[7]. Clough. Ray W, Penzien. J., Dynamics of Structures (McGraw-Hill. Inc. 1993).

[8]. Wilson, E.L., Three-Dimensional Static and Dynamic Analysis of Structures: A Physical Approach with Emphasis on Earthquake Engineering. Computers and Structures, Inc, Berkeley, California, 1996. 